\section{General Medical}

Council programmes for reduction of errors and protection of patients

\section{Hatch}

of non-medical members. It has a statutory responsibility to maintain the medical register, inclusion in which is a prerequisite for anyone wishing to practice medicine in the United Kingdom. It recognises the fact that the performance of doctors embraces attitudes as well as knowledge and skills [1]. Through its Education Committee, it determines the standards of education for undergraduate medical students and monitors the performance of the universities in providing the required medical education and qualifying examinations. For UK graduates, entry onto the medical register follows a 1year period of provisional registration in the pre-registration house officer grade. For the majority of overseas graduates from outside the European Community, entry onto the medical register requires them to pass the examination held by the Professional and Linguistics and Assessment Board (PLAB) and a period of limited registration, practitioners and some are outside any managed health care system. The GMC is the only body in the UK which has the power to prevent doctors from practising medicine completely, wherever their place of work. Through its Standards, Education and other committees it issues a wide range of guidance to doctors on matters such as consent [4] and confidentiality [5].
Correspondence:

Professor David Hatch

Institute of Child Health

30 Guilford Street

UK-London WC1N 1EH \begin{abstract}
though more experienced doctors may be exempt from these requirements. In 1995 the GMC in collaboration with the medical Royal Colleges, who have responsibility for supervising postgraduate training and continuing medical education in the UK, established the specialist register which defines the criteria for independent specialist consultant practice. In its document "Good Medical Practice" it sets out clearly the standards expected of doctors, and applies these standards when carrying out its statutory responsibility for protecting patients from doctors whose conduct, health or performance are seriously deficient [2]. Many of the Royal Colleges and specialist associations in the UK, including Anaesthetists, General Practitioners, Obstetricians, Oncologists, Ophthalmologists, Radiologists and Surgeons have produced specialty-specific good practice guidelines for their speciality based on the GMC's guidance, and others are in the process of doing so. The Royal Colleges will have an increasing role to play in ensuring that their members maintain the standards of knowledge, skill and professional behaviour required by the GMC throughout their working lives.

\section{Disciplinary functions of the GMC}

The GMC has the power to put conditions on doctors' registration and to impose temporary suspension or permanent erasure from the register. Most doctors in the UK work in the National Health Service, and come under the contractual authority of the Government's Department of Health, and the GMC has also issued guidelines to help managers to deal with doctors with problems [3]. Many doctors also work as independent

In the United Kingdom, the General Medical Council (GMC), established by Act of Parliament in 1858, is nises the need to have significant non-medical input and twenty-five percent of its Council is composed

Introduction
\end{abstract}




\section{Figure 1}

The framework for revalidation.

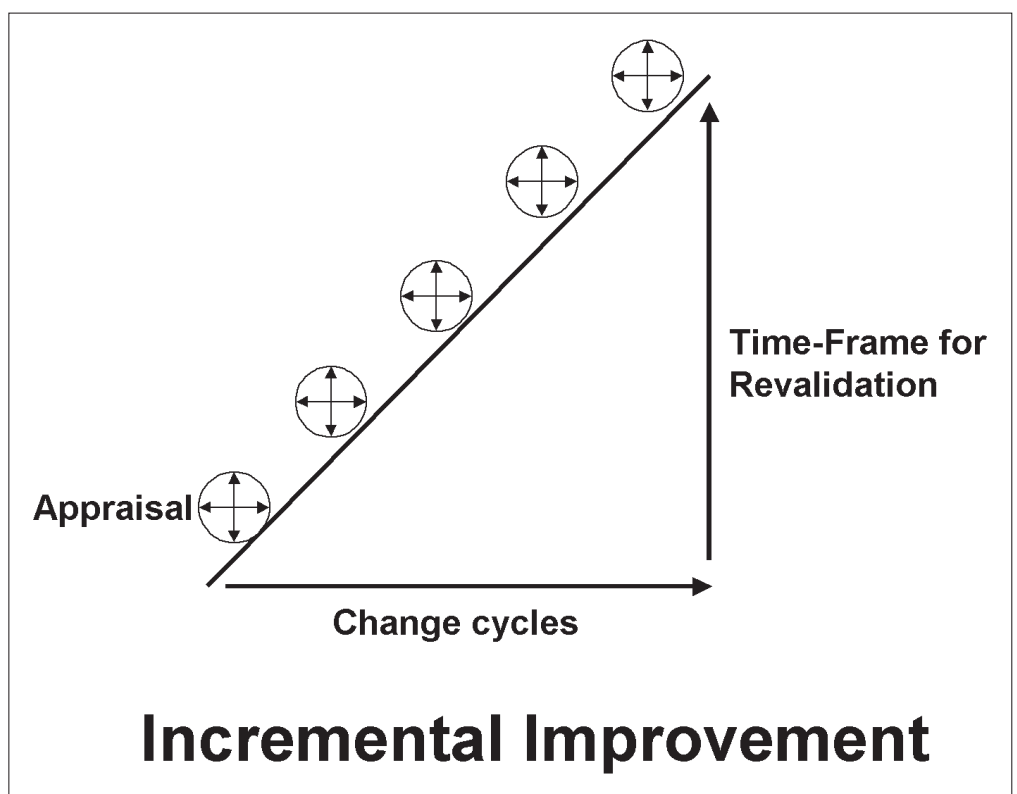

\section{Conduct procedures}

In the past, doctors could remain on the medical register permanently on payment of an annual retention fee unless they were found guilty of "serious professional misconduct" by the GMC. All doctors found guilty of criminal offences by the courts in the UK are reported by the police to the GMC, whose Professional Conduct Committee (PCC) decides whether the doctor's medical registration should be affected, either by the imposition of restrictions, by temporary suspension or permanent erasure. The PCC also hears allegations of serious professional misconduct made by members of the public or by persons acting in a public capacity such as representatives of hospitals or health authorities. The hearing is advocative, with both the doctor and the GMC being legally represented, and the standard of proof is that required by the UK criminal courts - "beyond reasonable doubt". Because of the specific nature of the allegations which the committee addresses, concerns which may arise during the hearing about other aspects of the doctor's professional performance or behaviour cannot be investigated. For this reason, among others, it became apparent during the early 1990's that there was a serious deficiency in the GMC's procedures which prevented it from dealing with doctors whose general standards of professional performance, whilst not raising issues of misconduct, were posing potential or actual threats to patient safety. This deficiency has been filled by the introduction of the performance procedures described below.

Health Procedures

In 1980 , the health procedures were introduced to deal with doctors suffering from seriously impaired health. These procedures are inquisitorial rather than advocative, and whilst patient safety is the foremost consideration they also offer the chance of remedial treatment for the doctor. Most doctors dealt with under these procedures are suffering from psychotic disorders, drug or alcohol abuse.

\section{Performance Procedures}

In 1997 the GMC introduced its performance procedures. These enable exploration of patterns of performance which may be deficient and whilst they are primarily designed to protect the public, they also provide an opportunity for retraining and rehabilitation of poorly performing doctors when this is possible. They are primarily designed to assess performance - what a doctor actually does, rather than competence - what the doctor is capable of doing. Whilst an incompetent person is by definition incapable of performing consistently to an acceptable standard, a competent one may or may not do so, depending on other factors such as stress, health, attitude or adverse environmental influences. Where the performance assessment provides evidence suggesting areas of incompetence a separate assessment of knowledge and skills may be required. The procedures, which have been introduced after extensive consultation with international experts on performance assessment, have four stages.

\section{Screening}

All allegations are subject to an initial screening process undertaken by medical and non-medical screeners who assess whether the allegation is serious enough to raise questions about the doctor's continued unrestricted registration. If so, they must then decide whether the case should be considered primarily as one of serious professional misconduct, seriously impaired health or seriously deficient performance. Even good doctors can make errors and these should not necessarily blight an otherwise unblemished career, even if the consequences are serious. In these situations, it is important to identify any improvements in managerial systems which can minimise the risk of adverse outcome, as discussed elsewhere [6]. Unless the error raises issues of serious professional misconduct, seriously impaired health or seriously deficient performance it is not a matter for the GMC. Unless both medical and non-medical screeners agree that no such issues arise, the case proceeds to the second stage, that of assessment. In practice, most allegations about the performance of doctors are made by people acting in a public capacity, and usually contain evidence of persistent failure to comply with the standards set in the GMC's document, "Good Medical Practice" [2]. However, even single errors may result from incompetence or from other remediable factors including ill health, the effect of stress, attitudinal or environmental issues. A single, serious allegation may also be of such a nature as to suggest that the doctor may have deficiencies in several areas of practice. 


\section{Assessment}

Doctors accused of seriously deficient performance are invited to undertake an assessment on a voluntary basis. The GMC does, however, have the power to order an assessment if necessary, subject to the safeguard of an appeal mechanism. Doctors who agree to voluntary assessment may avoid the stress of committee proceedings, though patient safety is the first consideration at all times.

The assessment is carried out over a period of 2-3 days at or near the doctor's place of work by a team of at least three assessors, appointed and trained by the GMC. Two of the assessors are medical, drawn from the same speciality as the doctor being assessed and the third assessor is non-medical. A third medical assessor may be involved in specific cases where sub-specialty or other issues arise.

The assessment tools include:

\section{Portfolio Assessment}

Before the visit of the assessors, the doctor is required to complete a detailed portfolio describing not only his or her curriculum vitae but also providing a job description of the current duties undertaken. This allows the assessors to tailor the assessment to the doctor's actual current practice. The portfolio also includes a self-assessment section in relation to the individual competencies required of the doctor in relation to the job description. This section gives the assessors an initial indication of whether the doctor has any insight into areas of deficiency and this selfassessment exercise can later be compared with other aspects of the assessment process.

\section{Structured Interviews}

These are held with people who can shed light on the doctor's performance and may include medical, nursing, ancillary, managerial and other staff. The doctor under assessment may nominate some of the interviewees. Ramsey has suggested that a minimum of 11 peer review ratings are required for reliability [7].

\section{Record Review}

A random selection of the doctor's medical records, usually at least 50, are selected for assessment using a structured template designed by the GMC. A subset of records is selected for subsequent case-based interview in order to allow the doctor to explain or defend actions recorded in the records.

\section{Environmental Assessment}

It is extremely important to assess the effect of environmental factors on the doctor's performance. The assessors therefore evaluate any effect of the environment in which the doctor works, eliciting any evidence to suggest that the doctor may be a victim of factors outside his or her control. Conversely doctors, especially those with managerial responsibilities, may be contributing to an adverse environment.

\section{Final Structured Interview}

A final interview is held with the doctor in which all the evidence gained at the assessment is brought to- gether to give the doctor an opportunity to correct any misunderstandings and challenge any factual evidence of poor performance arising at the assessment. The concept of triangulation - using a number of different sources of evidence, usually at least three, to confirm concerns about specific areas of practice - is used to increase the reliability of the assessment.

If this assessment produces evidence that there may be serious deficiencies in the doctor's competence, a second stage objective test of knowledge and clinical skills may be carried out, again, tailored to the doctor's actual practice. The tests used in this stage have all been validated using appropriate groups of peers against whom no allegations of deficient performance have been made.

\section{Retraining}

Doctors found to be seriously deficient in their performance may be required to undertake a programme of retraining, where this is possible. During this period their medical registration may be subject to restrictions or suspension in order to protect the public.

\section{Reassessment}

After retraining a further assessment is required before the doctor can return to unrestricted practice. Those doctors whose deficiencies are deemed irremediable and those who refuse to comply with the GMC's requirements are liable to suspension from the medical register, and hence from medical practice, initially for a limited period, followed if necessary by indefinite suspension.

\section{Revalidation}

The GMC's disciplinary procedures, outlined above, all suffer from the disadvantage that they depend on local reporting of doctors to the central regulatory body. Recent high-profile cases of unsafe practice and concerns about delays in reporting doctors who are known by their colleagues to pose a threat to patient care have led the GMC to decide that in future all doctors wishing to remain on the medical register must demonstrate regularly by a performance based system of revalidation that they remain fit to practice in their chosen field. The public now seeks assurances that doctors remain capable and safe throughout their practising lives [8]. Hopefully revalidation will give the public this assurance and confidence in the fact that registration with the GMC is synonymous with fitness to practice. At present entry on the register signifies little more than the fact that at some time in the past the doctor was held to be of a sufficient standard to be accepted onto the register, and that the GMC has not subsequently been informed of and tested any serious concerns which would bring continued registration into question. The implications of revalidation for specific groups of doctors have been described elsewhere [9].

For the vast majority of doctors, revalidation will provide an opportunity to demonstrate good practice in accordance with the GMC's document "Good Medical Practice". This sets out the duties and responsibilities of doctors and codifies what the public and 
Table 1

Areas of Good Medical Practice [2].

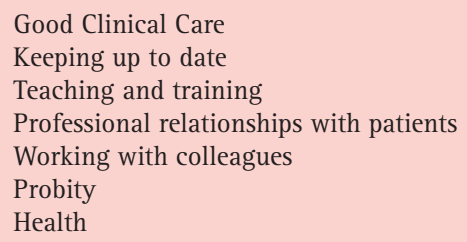

the medical profession agree is expected of each doctor [2]. Revalidation will encourage managers to provide doctors with time to reflect on their practice and introduce systems to encourage continual improvement. For a small minority who demonstrate weaknesses in their professional practice, it will provide an opportunity to put things right and give the GMC power to restrict or suspend registration if all else fails. The explicit linkage of professional standards of practice with GMC registration will ensure that individual doctors can be held properly accountable for their competence, performance and conduct throughout their active professional lives.

Revalidation will be a continuous process based on annual appraisal and the onus will be on the doctor to accumulate evidence of satisfactory performance in all aspects of "Good Medical Practice". These include clinical care, professional relationships with patients, working with professional colleagues, teaching and training where relevant and evidence of probity and health (Table 1). Possible sources of evidence include continuing medical education, at least some of which should be targeted to the doctor's actual field of practice, structured reports from colleagues along the lines of the Ramsey questionnaire [7], evidence of participation in audits that have changed clinical practices, lessons learnt from critical incident reports and complaints, patient satisfaction surveys, feedback from teaching and declarations of probity and health. The evidence will be subject to 5-yearly audit by joint medical and non-medical teams of assessors trained and appointed by the GMC. This 5-year time frame will give opportunity for local remedial action to deal with any weaknesses identified in annual appraisals where this is sufficient and practical (fig. 1). Local mechanisms for identifying the managerial and professional issues arising from errors or other causes of adverse clinical outcomes are currently inadequate. There has been reluctance among medical and non-medical staff to report concerns about colleagues, even when they pose potential or actual threats to patient care. The confidential "three wise men" peer support system has been widely discredited as ineffective and inconsistent [10]. Clinical audit, though mandatory in the $\mathrm{Na}$ tional Health Service, has not been introduced universally, and all too often audit loops are not closed. Local critical incident reporting schemes are gradually being introduced, but are not fully developed, and complaints are handled badly on too many oc- casions. The GMC's guidance makes it clear that doctors have a professional obligation to act quickly to protect patients from risk if they have good reason to believe that they or a colleague may not be fit to practise [2]. Where local action is insufficient, impractical, or fails, doctors employed by the National Health Service in England and Wales may be referred to the Government's newly established National Clinical Assessment Authority that will provide advice on any action which ought to be taken. If there is clear and immediate danger to patients, doctors will be referred to the GMC without delay. Similarly, those doctors who fail to provide robust evidence to demonstrate their fitness to practise in their chosen field to the Revalidation Committee will also be referred to the GMC.

Professionally led revalidation must complement managerially led clinical governance initiatives. A system of mandatory annual appraisal will be introduced for all doctors working in the National Health Service from April 2001. This will be a formative process, but should allow the appraiser to help the appraisee accumulate a folder of evidence in all the areas described above over a five year period. If appraisal works well there should be no surprises for the doctor at the time of revalidation, as issues giving rise to concerns should have been addressed locally at an early stage. For this to be achieved there needs to be a change in culture from the present blame-centred and litigious one to a no-blame environment where errors and deficiencies can be handled in a positive manner. Revalidation can provide a clear set of professional standards and support good practice and can remove dangerous doctors from all forms of practice requiring registration. Clinical Governance can take swifter local action and can more easily act proportionately to the size of the problem.

\section{References}

1 Irvine D. The performance of doctors. I: Professionalism and self regulation in a changing world. Br Med J 1997; 314:1540-2.

2 Good Medical Practice. London: General Medical Council; 1998.

3 Maintaining Good Medical Practice. London: General Medical Council;1998.

4 Consent to Treatment, Investigation \& Screening. London: General Medical Council; 1999.

5 Confidentiality: Protecting \& Providing Information. London: General Medical Council; 2000.

6 Hatch DJ. Incidence and Acceptance of Errors In Medicine. Swiss Med J 2001;82:1339-43.

7 Ramsey PG, Wenrich MD, Carline JD, Inui TS, Larson EB LoGerfo JP. Use of peer ratings to evaluate physician performance. JAMA 1993;269:1655-82.

8 Irvine D. The performance of doctors. II: Maintaining good practice, protecting patients from poor performance. Br Med J 1997;314:1613-5.

9 Hatch DJ. Revalidation, Poor Performance and Clinical Governance. In: Lugon M, Secker-Walker J (eds.). Advancing Clinical Governance. London: RSM Press; 2001. p.149-61.

10 Rosenthal MM. The incompetent doctor: behind closed doors. Buckingham: Open University Press; 1995. 